\title{
Positional cloning of the PIS mutation in goats and its impact on understanding mammalian sex-differentiation
}

\author{
Eric PAILHOUX ${ }^{\mathrm{a} *}$, Bernard VIGIER $^{\mathrm{a}}$, Laurent SCHIBLER ${ }^{\mathrm{b}}$, \\ Edmond P. CRIBIU ${ }^{\mathrm{b}}$, Corinne COTINOT ${ }^{\mathrm{a}}$, Daniel VAIMAN ${ }^{\mathrm{c}}$ \\ ${ }^{\text {a }}$ Laboratoire de biologie du développement et reproduction, Institut national de la recherche \\ agronomique, 78352 Jouy-en-Josas Cedex, France \\ ${ }^{\mathrm{b}}$ Laboratoire de génétique biochimique et cytogénétique, Institut national de la recherche \\ agronomique, 78352 Jouy-en-Josas Cedex, France \\ ${ }^{\mathrm{c}}$ Laboratoire de génétique et épigénétique des pathologies placentaires, INSERM-U361, \\ Pavillon Baudelocque, 123 Bd Port-Royal, 75014 Paris, France
}

(Accepted: 7 May 2004)

\begin{abstract}
In goats, the PIS (polled intersex syndrome) mutation is responsible for both the absence of horns in males and females and sex-reversal affecting exclusively XX individuals. The mode of inheritance is dominant for the polled trait and recessive for sex-reversal. In XX PIS $^{-/-}$mutants, the expression of testis-specific genes is observed very precociously during gonad development. Nevertheless, a delay of 4-5 days is observed in comparison with normal testis differentiation in XY males. By positional cloning, we demonstrate that the PIS mutation is an 11.7-kb regulatory-deletion affecting the expression of two genes, PISRT1 and FOXL2 which could act synergistically to promote ovarian differentiation. The transcriptional extinction of these two genes leads, very early, to testis-formation in XX homozygous $\mathrm{PIS}^{-/-}$mutants. According to their expression profiles and bibliographic data, we propose that FOXL2 may be an ovary-differentiating gene, and the non-coding RNA PISRT1, an anti-testis factor repressing $S O X 9$, a key regulator of testis differentiation. Under this hypothesis, $S R Y$, the testis-determining factor would inhibit these two genes in the gonads of XY males, to ensure testis differentiation.
\end{abstract}

PIS mutation / goat / gonad differentiation / XX sex-reversal / ovary development

\section{HISTORY OF THE MUTATION}

Spontaneously occurring hornless mutants exist in various ruminant species. They are particularly appreciated in farming since they make it unnecessary to surgically withdraw the horns, an operation currently performed on cattle and goats. In the early 1920's, pedigree analysis in goats indicated that

\footnotetext{
*Corresponding author: pailhoux @ jouy.inra.fr
} 
hornlessness is monogenic, autosomal and dominant. This situation made it particularly easy to produce large herds of hornless goats, and the mutation, called Polled $(\mathrm{P})$, has been extensively used in crosses in many countries (Eastern Europe, Switzerland, France, South America, Israel...). One surprising issue of hornless goat herds is the existence of abnormal sex-ratios, with an excess of male animals, amongst which many are in fact sterile. Some of these males appear as sex-reversed XX individuals, since the genetic sex is discordant from the phenotypic sex. A key linkage between hornlessness and intersexuality was published as early as 1944 [1], indicating unambiguously that whereas hornlessness is inherited in a dominant fashion, intersexuality is recessive. Other XX male sex-reversals have been identified in many mammalian orders, but only in goats is the phenotype so clear-cut, to the point where genetic females can be confounded with normal males. The existence of a visible marker (absence of horns) makes goats a very interesting model for identifying key sex-determining genes in mammals. Beside its sex-reversing effect on XX individuals, the Polled mutation (renamed PIS for polled intersex syndrome) is also responsible for infertility in $\mathrm{PIS}^{-/-} \mathrm{XY}$ individuals, resulting apparently from a mechanical obstruction of the epididymis. Also, heterozygous $\mathrm{PIS}^{+/-}$individuals appear mildly hyperfertile.

\section{LINKAGE ANALYSIS OF THE PIS MUTATION}

With the development of genomic tools and especially microsatellite markers, linkage analysis of the PIS mutation has become possible. Taking advantage of the dominance of the hornless trait, families were collected in French herds, and genome scanning located the mutation to goat chromosome 1 on band $1 \mathrm{q} 43[14,15]$. Its genetic localization was then refined by the targeted isolation and genotyping of new microsatellite markers using comparative mapping and selected chromosomal fractions. The PIS interval was thus reduced to a $\sim 1 \mathrm{cM}$ region of CHI1q43. The human homologous region was precisely identified as a HSA3q23 DNA segment encompassing the $C O P B 2$ gene formerly "COP" [16].

In order to clone the PIS mutation, a chromosome walk inside the region of interest has been realized, leading to the isolation of $91 \mathrm{BAC}$ from a constructed goat BAC library [11]. This led to the construction of six BAC contig elements of CHI1q43 (ICC1 to ICC6) covering altogether $4.5 \mathrm{Mb}$, one of which (ICC3, $1500 \mathrm{~kb}$ ) encompasses the PIS locus (Fig. 1). Thirty polymorphic microsatellites were isolated from this $4.5 \mathrm{Mb}$ region. Genotyping showed that ICC 3 encompasses a $\sim 400 \mathrm{~kb}$ interval where no recombinants are 


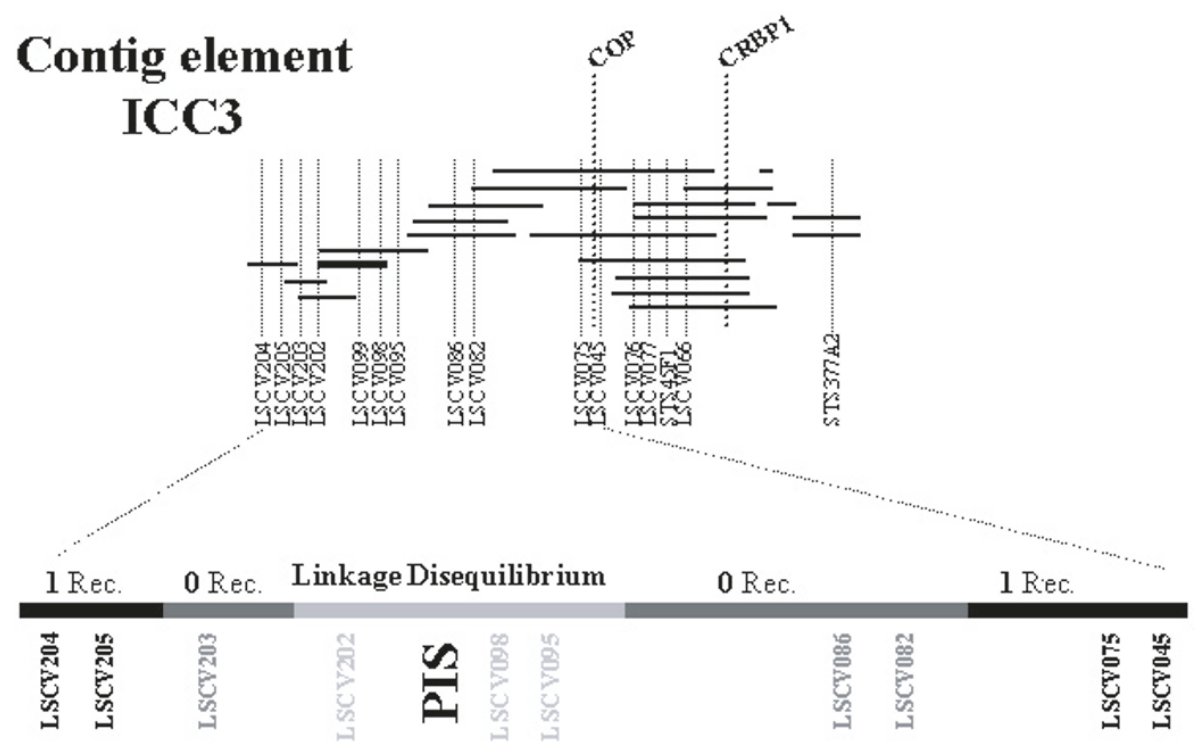

Figure 1. Details of the sub-contig ICC3 enclosing the PIS mutation. The lines in the upper part represent the BAC (the thick one: BAC 376H9). The lower part represents different genomic regions surrounding the mutation, with 1 recombinant (black) to 0 recombinants, and in the middle the region presenting a linkage disequilibrium (light grey). The position of two genes (COPB2 and $R B P 1)$ with those of 16 genetic markers (LSCV or STS) are indicated by dotted lines.

observed inside the resource families. Furthermore, a strong linkage disequilibrium among unrelated animals was detected with the two central markers of this region, suggesting a probable location for PIS in a $\sim 100 \mathrm{~kb}$ DNA region contained in one BAC (376H9). High resolution comparative mapping with human data shows that this DNA segment is the homologue of the human region associated with Blepharophimosis Ptosis Epicanthus inversus Syndrome, BPES [12]. This finding suggests that a homologous gene(s) could be responsible for the pathologies observed in humans and goats.

\section{POSITIONAL CLONING OF THE PIS MUTATION}

Four microsatellites were isolated from the goat BAC 376H9, making it possible to characterize haplotypes associated with the PIS mutation. In order to characterize this BAC transcriptionally, it was subcloned in a specific exon-trapping vector. The subclones were transfected into COS-7 cells, exogenous mRNA was prepared and reverse-transcribed $12 \mathrm{~h}$ after transfection. 
Sequencing made it possible to obtain 20 putative exons, one of which displayed a specifically gonadal pattern of expression. This element belongs to a $1.5 \mathrm{~kb}$ transcript without an open reading frame that we called PISRT1 for PIS-regulated transcript 1 . In order to physically position the coding and noncoding markers inside $376 \mathrm{H} 9$, a systematic sequencing approach was used. The BAC was first subcloned in large $(\sim 10 \mathrm{~kb})$ plasmid inserts, which were then sequenced by a primer-walking approach. The sequences were then assembled on $\sim 70 \mathrm{~kb}$ of the BAC. By haplotype analysis, the mutation was located between the two markers LSCV210 and LSCV211. The number of recombinant haplotypes between these two markers suggested that they are physically separated by $\sim 25$ kilobases. A targeted effort was performed towards this region, that could not be cloned in large plasmids due to its richness in repetitive sequences. Each progress in the sequence was monitored by PCR on genomic DNA from normal and PIS $^{-/-}$individuals. This screen enabled us to define a deleted element in all affected individuals. Sequencing through the deletion made it possible to define an $11.7 \mathrm{~kb}$ DNA fragment that is missing in mutant goats (Fig. 2). This element is composed for $80 \%$ of two copies of a partial ruminant LINE (2.2 and 2.6 kilobases), oriented head to head, 25 kilobases apart from PISRT1. There is no evidence of any coding sequence in the deleted fragment, suggesting that it probably affects the expression of this chromosome region by a long-range effect on chromatin structure [8].

\section{PIS IS A TRANSCRIPTIONAL REGULATORY REGION}

Expression of PISRT1 was studied first. This gene has a dimorphic expression pattern in the gonads of normal fetuses, with higher levels in the ovaries compared with testes during fetal life. Expressional studies were also performed on FOXL2, following its isolation in humans and its characterization as the gene responsible for BPES (OMIM 110100). This dominant syndrome leads to eyelid malformation in both sexes associated with female infertility [4]. In goats, FOXL2 was localized at around $300 \mathrm{~kb}$ from the PIS deletion (Fig. 2).

The PISRT1 and FOXL2 transcription levels are found to be sexually dimorphic in the gonads from 36 days post-coïtum ( $\mathrm{d} p c)$, a stage corresponding to the beginning of testicular formation in males [9]. The expression levels of the two genes are higher in ovaries than in the testes of normal fetuses. Using FOXL2specific antibodies, the protein has been investigated in the gonads of both sexes and has only been detected in the ovaries from $36 \mathrm{~d} p c$ to adulthood [3]. In XX PIS ${ }^{-/-}$sex-reversed gonads, transcription levels were greatly reduced 
$300 \mathrm{~kb}$

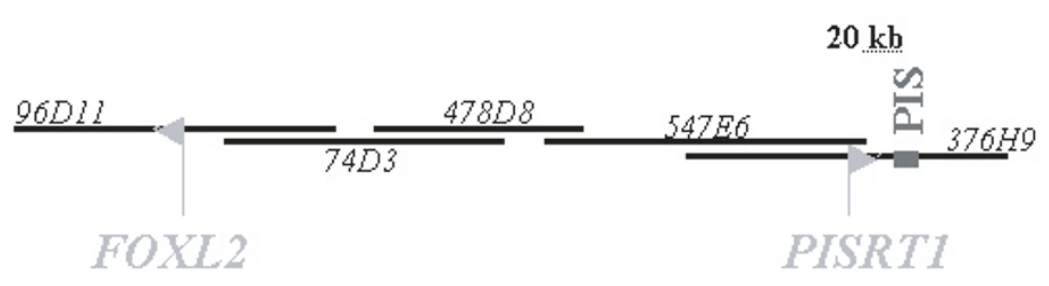

Figure 2. Schematic representation of the PIS region. The PIS mutation is represented on the right. It contains transcriptional regulatory elements of two genes (arrowheads), PISRT1 and FOXL2, located at 20 and $300 \mathrm{~kb}$ from PIS, respectively. The lines represent the different BAC encompassing the region. The BAC addresses are given in italics.

as early as $36 \mathrm{~d} p c$ for FOXL2 (Fig. 3) and only four days later, at $40 \mathrm{~d} p c$, for PISRT1. When studied at later stages (56, $70 \mathrm{~d} p c$ and after birth), the transcription levels of these two genes remain practically undetectable in homozygous $\mathrm{PIS}^{-/-}$sex-reversed gonads [8]. Moreover, FOXL2 transcription levels were found to be similar between normal $\mathrm{PIS}^{+/+}$and heterozygous $\mathrm{PIS}^{+/-}$ovaries. This may explain why the heterozygous goats are fertile, as opposed to heterozygous $F O X L 2^{+/-}$women affected by BPES type I [5].

FOXL2 and PISRT1 are also expressed in goat developing eyelids (studied at $36 \mathrm{dpc}$ ), but their transcriptional levels are not affected by the PIS mutation, in accordance with the fact that there is no BPES phenotype in goats. In contrast, the transcriptional regulatory action of the PIS region on the two genes is also visible in the horn buds. Expression of PISRT1 and FOXL2 significantly increased in the horn buds of PIS $^{-/-}$and PIS $^{+/-} 70 \mathrm{~d} p c$ fetuses, as compared with PIS $^{+/+}$controls [8].

In summary, the transcriptional effects of the PIS mutation are in complete agreement with the mode of inheritance of both traits. The polled trait is dominant and results from a gain of function mutation, precisely a gain of expression for the two genes. The XX sex-reversal trait is recessively inherited and results from a loss of function mutation (loss of expression). However, the role of each gene in the two phenotypes remains to be determined.

\section{REPLACEMENT OF THE PIS-REGULATED GENES IN THE GONAD-DIFFERENTIATING CASCADE}

Sex determination is governed by a series of genetic switches that influence cell fate and differentiation during critical periods of gonadal development. 

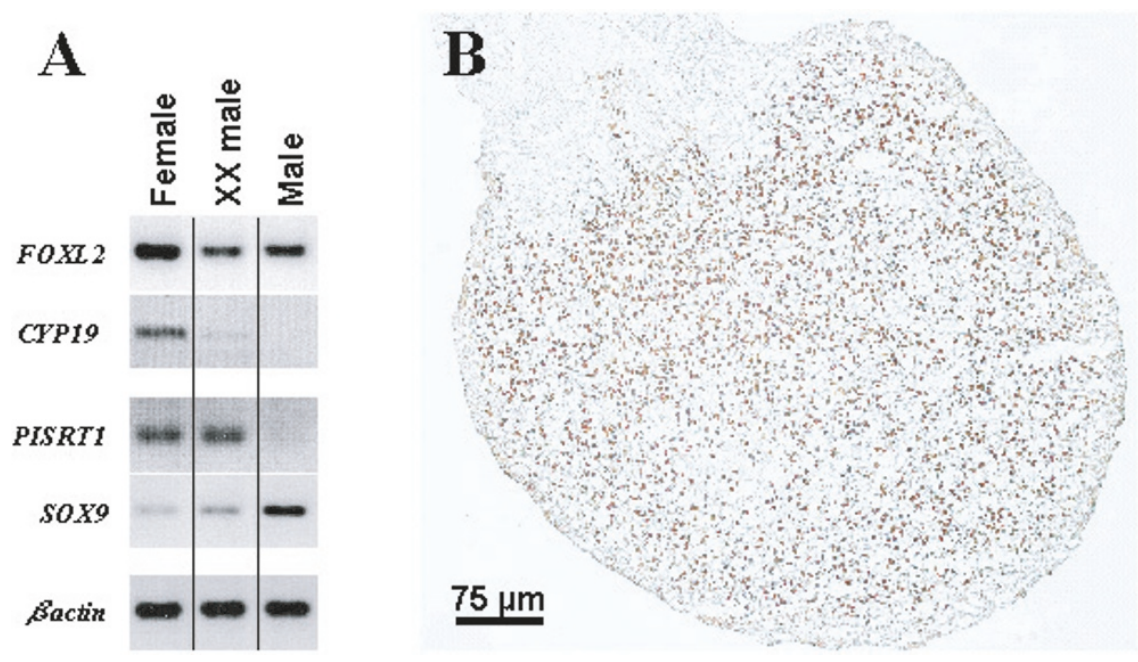

Figure 3. Expression profiles of sex-differentiating genes in the gonads of goat fetuses. (A) RT-PCR analysis of the PIS-regulated genes (PISRT1 and FOXL2) with two other genes (SOX9 and CYP19 encoding the cytochrome P450 aromatase) in the genital ridges (gonad + mesonephros) of 36 d $p c$ fetuses. At this stage, FOXL2 expression is already affected in the XX sex-reversed gonads and the expression of CYP19 is decreased. In contrast, PISRT1 and SOX 9 expressions are the same as in the normal female. (B) Immuno-localization of the FOXL2 protein in a $45 \mathrm{~d} p c$ ovary. Despite the fact that some transcripts are detected in the male gonads (see in A), the protein FOXL2 has only been found in the ovaries and the eyelids.

In mammals, the identification of the testis-determining gene, $S R Y$, has been a pivotal first step towards the unravelling of this genetic pathway [2]. It is now clear that numerous other genes, in addition to $S R Y$, are necessary for normal testis development, such as $S O X 9, W T 1, S F 1, D A X 1$, etc. [6]. The analyses of these genes in humans with gonadal dysgenesis or sex-reversal, mouse models and using in vitro cell culture assays have revealed that sex determination results from a complex interplay between the genes in this network (Fig. 4). In contrast to the male pathway, few genes are known to be involved in ovary differentiation. Only two factors are known to be preferentially expressed in the early developing ovary of rodents, namely Daxl [13] and Wnt4 [17]. These factors appear to act primarily as repressors of male development, rather than as active female-promoting signals.

Among the genes regulated by the PIS locus, FOXL2, encoding a forkhead transcription factor appears as an early determinant of ovarian differentiation. Its sexually dimorphic expression in embryonic ovaries of humans, ruminants, mice, chickens, and turtles, representatives of phylogenetically distant 


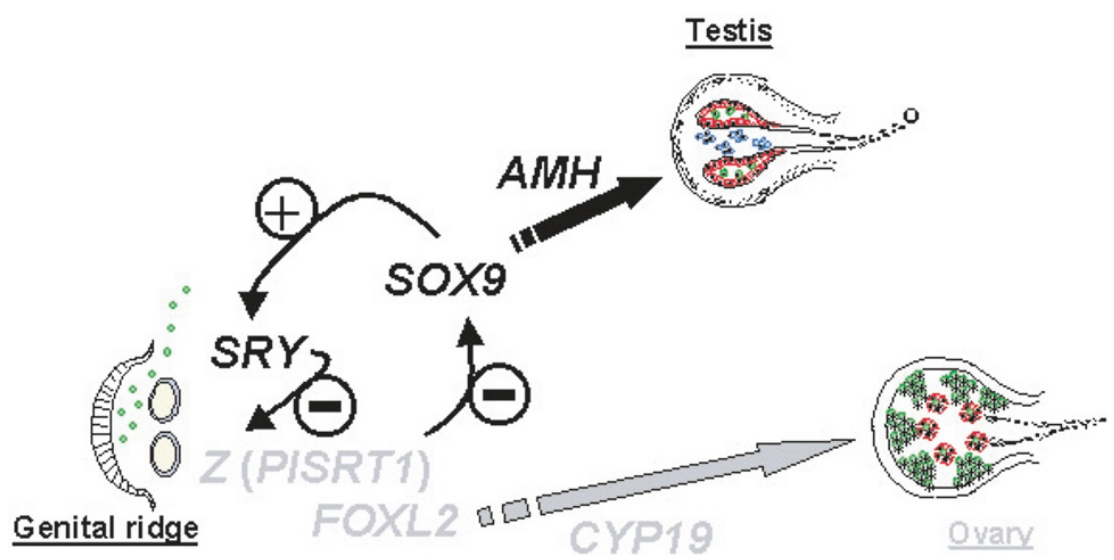

Figure 4. A schematic model of the sex-differentiation cascade with the PIS-regulated genes. In this model, FOXL2 regulates CYP19 gene expression and is determinant for the differentiation of the ovary. PISRT1 acts as an anti-testis factor by inhibiting SOX 9 in the female pathway. Under this hypothesis, PISRT1 must be inhibited in the male pathway; the sole candidate for triggering this inhibition remains $S R Y$.

vertebrate groups, is consistent with a crucial role of FOXL2 in the ovarydifferentiation pathway $[3,4,7,10]$. In addition, mutations in the FOXL2 gene are responsible for BPES, a complex human disorder characterized primarily by malformations of the eyelids and other facial anomalies. Another key feature of BPES is gonadal dysgenesis or premature ovarian failure in a high proportion of female patients $[4,5]$. In PIS $^{-/-}$goats, in which FOXL2 expression is abolished, ovaries do not differentiate but testis-differentiation takes place inducing sex-reversal. The first molecular effect observed after the absence of FOXL2 expression is a decreased transcription of the CYP19 gene encoding the cytochrome $\mathrm{P} 450$ aromatase, responsible for the conversion of androgens into estrogens (Fig. 3). Moreover, the levels of aromatase transcripts were highly correlated with the expression profile of the FOXL2 gene in goats and chickens and both proteins co-localize in the same gonadal area (data not shown). These data indicate that FOXL2 may be considered as a possible regulator of aromatase gene expression in certain species of vertebrates. In adult mice, FOXL2 transcription was detected in some oocytes, as well as in the granulosa cells and in cells of the corpus luteum $[4,7,10]$. In conclusion, FOXL2 plays not only a primordial role in ovarian differentiation, but possibly also in follicle and oocyte maturation.

The second gene affected by the PIS mutation is a non-coding RNA, called PISRT1. Its expression is also suppressed in the ovaries of $\mathrm{PIS}^{-/-}$animals but 
later than FOXL2. Concomitantly with the PISRT1 expression decrease, SOX 9 expression is up-regulated and the testis-differentiation commences, as attested by the presence of AMH (Anti-Müllerian Hormone) and testicular cord formation. Based on this observation and the fact that mutations of FOXL2 alone are never associated to sex-reversed phenotypes but only with ovarian failure, we proposed that PISRT1 could be an inhibitory factor of male genes and especially of the SOX 9 gene. On this assumption, the absence of PISRT1 would be responsible for the masculinization of the $\mathrm{PIS}^{-/-}$female gonads by inducing SOX9. PISRT1 expression has also been studied in mice, where, in contrast to goats, it is only expressed in adult ovaries [10]. This observation reinforces the idea that two distinct mechanisms of sex-determination could exist in mammals. The first, specific for the mouse, in which Sry, the trigger of a male cascade, directly activates Sox9 which is then maintained to a male-specific threshold by an auto-regulatory loop. Rapidly Sry becomes unnecessary and its expression window is narrowed. In the second model, represented by ruminants and probably also humans, SRY inhibits anti-testis factors, such as PISRT1, via the PIS region (Fig. 4). This inhibition permits the activation of $S O X 9$ which must be maintained for a long time. This is consistent with the fact that in most mammals, SRY expression persists during a long period in order to initiate and maintain testis differentiation. Finally, the existence of a subtly-regulated balance between activator and repressor factors could participate in enhancing gene dosage sensibility of certain species, like humans, in sex-determination.

\section{ACKNOWLEDGEMENTS}

The authors would like to acknowledge the help of their collaborators in studies of goat sex-reversal: Stéphane Chaffaux, Marc Fellous, Jean-Pierre Furet, Anne Oustry-Vaiman, Nathalie Servel and Sead Taourit. We thank JeanFrançois Alkombre, Albert Brouille, Joseph Balluais, Raymond Lavergne, Jean-Michel Bastard, Joël Boulay and Christian Poirier (INRA - UCEA - Jouyen-Josas) for goat management.

\section{REFERENCES}

[1] Asdell S.A., The genetic sex on intersexual goats and a probable linkage with the gene for hornlessness, Science 99 (1944) 124.

[2] Berta P., Hawkins J.R., Sinclair A.H., Taylor A., Griffiths B.L., Goodfellow P.N., Fellous M., Genetic evidence equating $S R Y$ and the testis-determining factor, Nature 348 (1990) 448-450. 
[3] Cocquet J., Pailhoux E., Jaubert F., Servel N., Xia X., Pannetier M., De Baere E., Messiaen L., Cotinot C., Fellous M., Veitia R.A., Evolution and expression of FOXL2, J. Med. Genet. 39 (2002) 916-921.

[4] Crisponi L., Deiana M., Loi A., Chiappe F., Uda M., Amati P., Bisceglia L., Zelante L., Nagaraja R., Porcu S., Ristaldi M.S., Marzella R., Rocchi M., Nicolino M., Lienhardt-Roussie A., Nivelon A., Verloes A., Schlessinger D., Gasparini P., Bonneau D., Cao A., Pilia G., The putative forkhead transcription factor FOXL2 is mutated in blepharophimosis/ptosis/epicanthus inversus syndrome, Nat. Genet. 27 (2001) 159-166.

[5] De Baere E., Dixon M.J., Small K.W., Jabs E.W., Leroy B.P., Devriendt K., Gillerot Y., Mortier G., Meire F., Van Maldergem L., Courtens W., Hjalgrim H., Huang S., Liebaers I., Van Regemorter N., Touraine P., Praphanphoj V., Verloes A., Udar N., Yellore V., Chalukya M., Yelchits S., De Paepe A., Kuttenn F., Fellous M., Veitia R., Messiaen L., Spectrum of FOXL2 gene mutations in blepharophimosis-ptosis-epicanthus inversus (BPES) families demonstrates a genotype-phenotype correlation, Hum. Mol. Genet. 10 (2001) 1591-1600.

[6] Koopman P., The genetics and biology of vertebrate sex determination, Cell 105 (2001) 843-847.

[7] Loffler K.A., Zarkower D., Koopman P., Etiology of ovarian failure in blepharophimosis ptosis epicanthus inversus syndrome: FOXL2 is a conserved, early-acting gene in vertebrate ovarian development, Endocrinology 144 (2003) 3237-3243.

[8] Pailhoux E., Vigier B., Chaffaux S., Servel N., Taourit S., Furet J.-P., Fellous M., Grosclaude F., Cribiu E.P., Cotinot C., Vaiman D., A 11.7-kb deletion triggers intersexuality and polledness in goats, Nat. Genet. 29 (2001) 453-458.

[9] Pailhoux E., Vigier B., Vaiman D., Servel N., Chaffaux S., Cribiu E.P., Cotinot C., Ontogenesis of female-to-male sex-reversal in XX polled goats, Dev. Dyn. 224 (2002) 39-50.

[10] Pannetier M., Servel N., Cocquet J., Besnard N., Cotinot C., Pailhoux E., Expression studies of the PIS-regulated genes suggest different mechanisms of sex determination within mammals, Cytogenet. Genome Res. 101 (2003) 199205.

[11] Schibler L., Vaiman D., Oustry A., Guinec N., Dangy-Caye A.-L., Billault A., Cribiu E.P., Construction and extensive characterization of a goat Bacterial Artificial Chromosome library with threefold genome coverage, Mamm. Genome 9 (1998) 119-124.

[12] Schibler L., Cribiu E.P., Oustry-Vaiman A., Furet J.-P., Vaiman D., Fine mapping suggests that the goat Polled Intersex Syndrome and the human Blepharophimosis Ptosis Epicanthus Syndrome map to a 100-kb homologous region, Genome Res. 10 (2000) 311-318.

[13] Swain A., Zanaria E., Hacker A., Lovell-Badge R., Camerino G., Mouse Daxl expression is consistent with a role in sex determination as well as in adrenal and hypothalamus function, Nat. Genet. 12 (1996) 404-409. 
[14] Vaiman D., Koutita O., Oustry A., Elsen J.-M., Manfredi E., Fellous M., Cribiu E.P., Genetic mapping of the autosomal region involved in XX sex-reversal and horn development in goats, Mamm. Genome 7 (1996) 133-137.

[15] Vaiman D., Pailhoux E., Schibler L., Oustry A., Chaffaux S., Cotinot C., Fellous M., Cribiu E.P., Genetic mapping of the polled/intersex locus (PIS) in goats, Theriogenology 47 (1997) 103-109.

[16] Vaiman D., Schibler L., Oustry-Vaiman A., Pailhoux E., Goldammer T., Stevanovic M., Furet J.-P., Schwerin M., Cotinot C., Fellous M., Cribiu E.P., High-resolution human/goat comparative map of the goat polled/intersex syndrome (PIS): the human homologue is contained in a human YAC from HSA3q23, Genomics 56 (1999) 31-39.

[17] Vainio S., Heikkilä M., Kispert A., Chin N., McMahon A.P., Female development in mammals is regulated by Wnt-4 signalling, Nature 397 (1999) 405-409.

To access this journal online: www.edpsciences.org 